\title{
Ponencia Central en la Inauguración de la XVI Jornada Universitaria de Desarrollo Científico (JUDC). UNAN-FAREM-Estelí
}

\section{JUDC: INVESTIGO LUEGO INNOVO. Estelí, Nicaragua. 18 de Septiembre 2013.}

\section{Eduardo López H. Miembro del Concejo de Facultad UNAN-Nanagua FAREM-Estelí.}

Quiero iniciar esta ponencia haciendo alusión a dos momentos memorables en nuestra historia y que están relacionados con el pensamiento, con la reflexión, en primer lugar al dialogo entre El Cacique Nicarao y Gil González en 1523, lo central del dialogo es cuando Nicarao lo interroga: ¿El papa y el rey de los cristianos son Mortales? ¿Que honra se le debe al rey de los cristianos?, ¿Por qué se produce la oscuridad, el frío y el calor?, ¿Cómo se sostienen los astros en el firmamento y la energía de estos de donde surge? ¿Por qué, tan pocos hombres, querían tanto oro?, esas preguntas reflejaban un grado de abstracción científico-filosófico bien profundo.

En segundo lugar, cuando el Fraile Tomas Ruiz, defiende su tesis de Doctor en filosofía en la Universidad San Carlos de Guatemala y ante el jurado presidido por José Liendo y Goicoechea, uno de los hombres más ilustrados de Centroamérica, entre los siglos XVIII y XIX, Ruiz expreso: "Para la defensa de la verdad, es mejor el método socrático que el método escolástico".

Estos planteamientos hechos aproximadamente hace 490 y 214 años respectivamente, son un ejemplo imperecedero de quienes se plantearon interrogantes en la búsqueda de verdades objetivas que dieran respuestas pertinentes a las realidades de aquel entonces.

La universidad, como institución formadora de los profesionales del presente y del futuro del país, está siempre en la permanente búsqueda de verdades objetivas, por lo tanto, tiene una enorme responsabilidad frente a los desafíos que este siglo XXI nos plantea, sobre todo en materia de conocimientos, que con su acelerado avance nos obliga a reflexionar, a cuestionarnos sobre que tipo de educación hay que proponer, y para qué tipo de desarrollo, no obstante, el conocimiento por sí solo no es nada, se trata de saber utilizarlo, darle viabilidad y eso solo es posible desde una praxis educativa innovadora que tenga en la investigación la punta de lanza de los aprendizajes significativos de los estudiantes, para que el conocimiento de respuesta a su formación integral y al desarrollo de la sociedad en los aspectos técnicos, científicos, productivos, ambientales, económicos y culturales. 
La Declaración Mundial sobre la Educación Superior en el Siglo XXI: Visión y Acción (París, 1998), expresamente dice: "dado el alcance y el ritmo de las transformaciones, la sociedad cada vez tiende más a fundarse en el conocimiento. En razón de que la educación superior y la investigación forman hoy en día parte fundamental del desarrollo cultural, socioeconómico y ecológicamente sostenible de los individuos, las comunidades y las naciones, la propia educación superior ha de emprender la transformación y la renovación más radicales que jamás haya tenido por delante".

Estamos conscientes que como universidad, tenemos el reto de atender viejas y nuevas demandas, signadas por: Una sociedad del conocimiento y la información agresivos, un mundo globalizado, una economía más intensa en conocimiento, la variabilidad climática, retos en la producción y productividad, la integración regional, la innovación y el emprendedurismo, los desafíos en materia energética, el supremo sueño de Sandino el canal interoceánico, en fin, muchas más que debemos enfrentar con responsabilidad académica y científica desde nuestra Alma Mater y eso solo es posible cuando los aprendizajes parten: de la curiosidad, de la observación, del ensayo y el error, de lo que no está resuelto, de la competencia cognitiva, del yo empírico al sujeto epistémico.

La educación universitaria mediante la investigación y la innovación, deben motivar el desarrollo económico, sobre todo porque este último es cada vez más intenso en conocimiento, esto significa aprender desde la investigación, desde la innovación y esto ha venido siendo la JUDC. No podemos perder la perspectiva de que la JUDC, por su experiencia acumulada, por su pertinencia, es un aprendizaje de invaluable importancia que ha llevado a los protagonistas viejos y nuevos a tener una visión y una praxis holística de la realidad.

La JUDC, viabiliza los tres ejes fundamentales del quehacer universitario, es decir la docencia, la investigación y la extensión, las que conforman una unidad dialéctica fundamental en las tareas educativas de la universidad, la puesta en práctica de estos tres ejes de manera creativa, con visión holística, debe permitir la forja integral de los educandos, el crecimiento endógeno de la universidad y una proyección exógena que demuestre porque la universidad es una depositaria esencial de los planes de desarrollo de la nación.

- Docencia como praxis educativa que fortalece los aprendizajes significativos, que nos induce a la cultura científica.

- Investigación como el quehacer pedagógico de la universidad.

- Extensión: debe ser la mejor expresión de una integración creativa UniversidadSociedad. Es el empoderamiento cognitivo y actitudinal de los sectores sociales, lo cual es facilitado por la comunidad universitaria.

El Dr. Jaime Chahin, especialista en administración universitaria de la universidad estatal de Texas, indica que: "Nuestros estudiantes están preparándose para puestos que todavía no existen, las tecnologías que usaran todavía no se han inventado, tendrán que resolver problemas que todavía no conocemos." 
Pero nosotros, desde nuestra universidad también tenemos la capacidad de hacerlo y esto será posible, en la medida en que el proceso de transformación curricular de nuestra universidad genere el encadenamiento dialectico entre ciencia, conciencia, tecnología, y metodología en correspondencia con la realidad, con el entorno que nos rodea, con los retos que tenemos para transformar ese entorno y desde luego con el modelo educativo de la universidad, el que:

"Está centrado en las personas, que contribuye con el desarrollo integral de los estudiantes. Un modelo que articula las acciones de los diferentes actores participes en el quehacer educativo de la universidad, y que además, orienta la formación de profesionales con una concepción científica y humanista, capaces de interpretar los fenoles sociales y naturales con un sentido crítico, reflexivo y propositivo".

Y en el plan estratégico 2010-2015, donde se indica lo siguiente:

"La universidad tiene grandes retos: debe prevalecer su calidad sin menoscabar su crecimiento; debe mantenerse en la cúspide de sus planteamientos innovadores y de sus propuestas metodológicas, organizativas y curriculares; debe proyectarse como la universidad del futuro, la de mayor actualidad, la universidad cuya reserva moral impregne de profesionalismo a sus académicos y graduados y debe seguir siendo la Universidad Pública ejemplar, cuya rendición social de cuentas refleja el estado positivo de su avance".

Como también en el concepto de currículo:

"Hacer del alumno el centro del proceso educativo que exige nuevas formas de concebir las funciones sustantivas de docencia, investigación y extensión. Es por eso, que la universidad concibe al currículo como "Un proyecto educativo con un cuerpo organizado de conocimientos, habilidades, destrezas, valores y actitudes, destinado a provocar el encuentro del futuro profesional con la ciencia, la tecnología y la cultura"

Y en el campo de la investigación, se señala:

"La investigación universitaria de la UNAN Managua tendrá por finalidad la creación de conocimientos, el avance e innovación del conocimiento adquirido y su adaptación a las condiciones particulares del país. La investigación se desarrolla en el currículo de cada carrera por medio de los trabajos de cursos y de las jornadas universitarias de desarrollo científico. Su énfasis está en beneficio de la comunidad a nivel nacional y el desarrollo regional".

Estos postulados, estos referentes estratégicos de nuestra universidad implican un enorme reto, en los campos de la investigación, de la innovación, sobre todo en este mundo contemporáneo donde el conocimiento se vuelve obsoleto en muy poco tiempo. 
Resulta aleccionador para los retos que tenemos, lo que señala el Ministerio de Fomento Industria y comercio de nuestro país. "En Nicaragua se han registrado 300 patentes de invención entre 2006 y 2011. Es decir que en promedio por año el país generaría 50 patentes, sin embargo más del 70 por ciento de estas, pertenecen a compañías extranjeras que registran la patente de su producto para tenerlas protegidas en su uso localmente".

O la Organización Mundial de la Propiedad Intelectual (WIPO): "En cuanto al índice de innovación global en el año 2012, Nicaragua ocupa el puesto 105 de 141 países”.

No podemos dejar de señalar otros aspectos esenciales que están vinculados con lo que estamos abordando, me refiero a las Tecnologías de Información y Comunicación (TIC), la gestión del conocimiento y la popularización de la ciencia, veamos:

1. Las TIC: Son una herramienta de invaluable importancia para nuestro desarrollo educativo, pero desde la universidad debemos romper con el esquema infoglobalizantes versus infoglobalizados, o info-ricos versus info- pobres

El académico Joaquín Brunner indica que:

"No debe cometerse el error de imaginar que el cambio educacional será guiado por las nuevas tecnologías de información y comunicación, por poderosas que estas sean. La educación es mucho más que sus soportes tecnológicos; encarna un principio formativo, es una tarea social y cultural que, cualesquiera sean las trasformaciones que experimente, seguirá dependiendo, ante todo, de sus componentes humanos, ideales y valóricos".

2. La gestión del conocimiento: Es una tarea impostergable para los que estamos hablando de ciencia, haciendo ciencia permanentemente, muchas organizaciones hoy hablan de gestionar conocimiento en diferentes campos, agricultura, ganadería, medio ambiente, etc, y desde luego que nosotros somos los llamados a este tipo de gestión.

Tenemos un enorme reto como estudiantes, como profesionales, como miembros de la comunidad universitaria, en cuanto a elevar la calidad de la educación, en este sentido, gestionar el conocimiento, implica elevar nuestros niveles de formación, de investigación, de establecer colectivos científicos haciendo uso de la multidisciplinariedad, de la interdisciplinariedad, que nos encaminen no solo a encontrar la verdad, sino que también hacerla realidad a través de la praxis. Si la realidad es interdisciplinaria, la docenciaaprendizaje también lo debe ser (Brunner)

3. La popularización de la ciencia: "La universidad y su aporte al desarrollo comunitario, una alternativa de humanizar el conocimiento, de popularizar la ciencia. Vivimos en la sociedad del conocimiento, pero ¿De que sirve el conocimiento si no se realizan transformaciones en la sociedad? ¿De qué sirve una universidad que este de cara al conocimiento y de espaldas a la realidad? ¿Cómo llegar a los sectores más vulnerables?. 
Investigar e innovar potencia el desarrollo nacional, pero también social cuando se humaniza la ciencia”. (Brunner)

Humanizar el conocimiento es desarrollar como dice Paulo Freire "la pedagogía de la esperanza" que en palabras del educador significa: "Inyectar en esa gente desesperanzada el interés, las intenciones de superación, los sueños, y esto, es posible mediante la educación y la forma de llevarla a cabo. Por eso surge La Pedagogía de la Esperanza". Y la investigación como el quehacer pedagógico de la universidad y la pedagogía de la esperanza son ciencia y conciencia en el camino hacia la innovación y por el desarrollo del ser y el desarrollo local y nacional.

La cantidad de trabajos a presentar en esta JUDC, es el reflejo de lo que estamos haciendo, de la interdisciplinariedad de nuestro quehacer pedagógico y de la interdisciplinariedad del medio.

Compañeros miembros de la comunidad universitaria, no me queda la menor duda que estamos en el camino correcto, en un camino de continuidades y rupturas, esencialmente dialectico, de esperanzas y utopías y que vamos a enfrentar el futuro con la experiencia de 201 años de existencia de nuestra universidad y con la valentía y la reflexión filosófica de Nicarao y el talento académico y científico de Tomas Ruíz. 